\title{
Prediction of Oxy-Coal Flame Stand-off Using High-Fidelity Thermochemical Models and the One-Dimensional Turbulence Model
}

\author{
Babak Goshayeshi, James C. Sutherland
}

\begin{abstract}
An Eulerian one-dimensional turbulence (ODT) model is applied to simulate oxy-coal combustion, with specific aim at predicting flame stand-off distances. Detailed gas-phase chemical kinetics based on the GRI3.0 mechanism are utilized. A high-fidelity model for devolatilization is considered that predicts evolution of several light gas species as well as char as products of devolatilization. The mass, momentum and energy governing equations are fully coupled between the particle and the gas phase. Likewise, char oxidation and gasification are both considered. Results indicate that char oxidation and gasification are both significant during the later stages of devolatilization. The impact of radiative temperature and mixing rate on oxy-coal flame is simulated and discussed where flame stand-off is used as a metric to compare the simulation prediction with experimental data. The data show evidence that there is kinetic limitation to the flame standoff distance. Finally, results show that ODT can provide quantitative agreement with experimental data in predicting flame standoff in oxy-coal jet flames.
\end{abstract}

Keywords: One-dimensional turbulence; turbulent combustion; Coal combustion; Oxy-coal combustion; Devolatilization

\section{Introduction}

Among the promising technologies to capture $\mathrm{CO}_{2}$ for subsequent sequestration in new and existing coal-fired power plants is oxy-coal combustion. In the process of oxy-coal combustion, oxygen mixed with recycled flue gas is used as an oxidizer rather than air. Models to predict the physics of such a system must address the nonlinearly coupled processes of particle dynamics, gas-phase thermochemistry, heterogeneous reactions between the coal and gas, devolatilization/pyrolysis, vaporization, radiative heat transfer, etc. This multiscale (in both space and time) problem poses a significant modeling challenge.

Models for coal devolatilization vary widely in complexity. Arrhenius-form models such as single-rate [2] and Kobayashi [17] models are among the relatively simple models that describe devolatilization with a kinetic rate. The distributed activation energy model [1] uses a gaussian distribution for the activation energy. Among the more complex models, chemical percolation devolatilization (CPD) considers thermal decomposition of the macromolecular network and accounts for structural variation in coal types [3, 9, 33]. In a more advanced version of the CPD model, rate equations corresponding to various light gas species are utilized in order to predict the light gas composition [14], providing an opportunity to couple directly with detailed chemistry in the gas phase.

Numerous studies on oxy-coal combustion and gasification physics, in particular the ignition delay, flame stability and temperature, flame shape, impacts of oxygen and diluent have been undertaken (see, e.g., [5, 10, 12, 13, 20, 24]). Various experiments have measured the impact of coal type and operating conditions such as composition of coal transport medium on flame stand-off and stability [27, 39].
Applying direct numerical simulation (DNS) with detailed gas-phas kinetics and coal devolatilization models can help improve understanding of ignition and can provide a basis for evaluating simpler models. However, it remains prohibitively expensive to perform DNS in regimes relevant to practical coal combustion. In this work, an Eulerian formulation of the one-dimensional turbulence (ODT) model is used. ODT resolves the full range of length and time scales of the continuum (as in DNS) but in a single spatial dimension, thereby significantly decreasing the computational cost relative to DNS. First proposed by Kerstein [16], ODT has been successfully applied to a variety of turbulent flows, including particle-laden flows [30] and turbulence-chemistry interaction including extinction and reignition $[18,26]$. Most notable among the assumptions in ODT is that the flow field is statistically onedimensional (implications of this assumption are discussed in $[25,35])$. In this work, ODT is used to simulate oxy-coal flames and is evaluated against experimental data [28, 39].

The aim of this work is to assess the effects of system parameters as well as model parameters on the prediction of flame stand-off distance in a $40 \mathrm{~kW}$ coal combustor $[27,28]$, and to demonstrate the efficacy of the ODT model in modeling turbulent coal combustion. The impact of the "eddy rate constant" (which affects the mixing rate in ODT), radiative temperature, and primary $\mathrm{O}_{2}$ concentration on the flame stand-off is explored. This is the first work of its kind that determines flame stand-off distance using detailed kinetic calculation of the gas phase fully coupled to a high-fidelity model (CPD) for devolatilization of coal particles. 


\section{Governing Equations}

The equations governing gas and particle (coal) phases are summarized in this section.

\subsection{Gas Phase}

An Eulerian formulation of ODT [35] adapted to solve multiphase reacting flows is applied in this work. The conservation equations are

$$
\begin{aligned}
\frac{\partial \rho}{\partial t} & =-\frac{\partial v}{\partial y}+S_{\mathrm{p} m}, \\
\frac{\partial \rho v}{\partial t} & =-\frac{\partial \rho v v}{\partial y}-\frac{\partial \tau_{y y}}{\partial y}-\frac{\partial P}{\partial y}+S_{\mathrm{p} v}, \\
\frac{\partial \rho u}{\partial t} & =-\frac{\partial \rho v u}{\partial y}-\frac{\partial \tau_{y x}}{\partial y}+S_{\mathrm{p} u}, \\
\frac{\partial \rho e_{0}}{\partial t} & =-\frac{\partial \rho e_{0} v}{\partial y}-\frac{\partial p v}{\partial y}-\frac{\partial \tau_{y y} v}{\partial y}-\frac{\partial q}{\partial y}+S_{\mathrm{p} e_{0}}, \\
\frac{\partial \rho Y_{i}}{\partial t} & =-\frac{\partial \rho Y_{i} v}{\partial y}-\frac{\partial J_{i}}{\partial y}+\omega_{i}+S_{\mathrm{p} Y_{i}},
\end{aligned}
$$

where $u$ and $v$ refer to streamwise and spanwise velocities, respectively, mixture-averaged approximations are used for diffusive fluxes, and $P$ is obtained via the ideal gas equation of state. $S_{\mathrm{p} m}, S_{\mathrm{p} v}, S_{\mathrm{p} u}, S_{\mathrm{p} e_{0}}$ and $S_{\mathrm{p} Y_{i}}$ are interphase exchange terms for mass, $y$-momentum, $x$ momentum, total internal energy and species respectively (see \$2.3) and the p subscript denotes a particle-phase property. Here, the $y$-direction is taken as the spanwise direction. A reduced GRI mechanism consisting of 24 species and 86 reactions [32] is utilized for the gas-phase kinetics treatment. Transport equations are solved for the species, with appropriate phase-exchange source terms for the devolatilization, vaporization, and char oxidation processes occurring on particles.

\subsection{Particle Phase Governing Equations}

Newton's second law is employed to describe the motion of each particle

$$
m_{\mathrm{p}} \frac{\mathrm{d} u_{\mathrm{i}, \mathrm{p}}}{\mathrm{d} t}=m_{\mathrm{p}} g_{\mathrm{i}}+S_{\mathrm{p}, v}+F_{\mathrm{p}}
$$

where $i$ denotes the $i^{\text {th }}$ direction, $m_{\mathrm{p}}, u_{i, \mathrm{p}}, g_{\mathrm{i}}, S_{\mathrm{p}_{j}, v}$, and $F_{\mathrm{p}}$ are mass of single particle, particle velocity, gravity acceleration, force generated by fluid-particle interaction, and force generated by particle-particle interaction. For this study, particle-particle interaction is neglected $\left(F_{\mathrm{p}}=0\right)$ and the drag force is described by Stokes' law so that the particle momentum equations become

$$
\frac{\mathrm{d} \vec{u}_{\mathrm{p}_{\mathrm{j}}}}{\mathrm{d} t}=\frac{\vec{g}_{i}\left(\rho_{\mathrm{p}}-\rho_{\mathrm{g}}\right)}{\rho_{\mathrm{p}}}+S_{\mathrm{p}, \vec{u}}
$$

where $\left(S_{\mathrm{p}_{\mathrm{j}}, \vec{u}}\right)$ is given by Eq. (11) in $\S 2.3$. The position of the $j^{\text {th }}$ particle in the $i^{\text {th }}$ direction $\left(x_{i, \mathrm{p}_{j}}\right)$ is determined by

$$
\frac{\mathrm{d} x_{i, \mathrm{p}_{\mathrm{j}}}}{\mathrm{d} t}=u_{i, \mathrm{p}_{\mathrm{j}}}
$$

The energy conservation equation for each particle is

$$
\frac{\mathrm{d} T_{\mathrm{p}}}{\mathrm{d} t}=\frac{-A_{\mathrm{p}}}{m_{\mathrm{p}} C_{\mathrm{p}}}\left[h_{c}\left(T_{\mathrm{p}}-T_{\mathrm{g}}\right)+\varepsilon \sigma\left(T_{\mathrm{p}}^{4}-T_{\mathrm{rad}}^{4}\right)\right]+S_{\mathrm{p}, T},(9)
$$

where $T_{\mathrm{p}_{j}}, T_{\text {rad }}$ and $T_{\mathrm{g}}$ are the particle, radiative, and gas temperatures respectively. $C_{\mathrm{p}}, m_{\mathrm{p}}, A_{\mathrm{p}}$ and $\epsilon$ are the particle heat capacity, mass, surface area and emissivity, respectively, $\sigma$ is the Stefan-Boltzmann constant, $h_{c}=N u \lambda / d_{\mathrm{p}}$ is the convective heat transfer coefficient with $\mathrm{Nu}=2.0+$ $0.6 \operatorname{Re}_{\mathrm{p}}^{1 / 2} \operatorname{Pr}^{1 / 3}[11]$, and $S_{\mathrm{p}, T}$ is the temperature source term due to vaporization and heterogeneous reactions defined by Eq. (14). In this work, radiation is considered only between particles and an "effective" furnace environment at $T_{w}$.

The mass $\left(m_{\mathrm{p}}\right)$ of each coal particle evolves as

$$
\frac{\mathrm{d} m_{\mathrm{p}}}{\mathrm{d} t}=\frac{\mathrm{d} m_{\mathrm{w}}}{\mathrm{d} t}+\frac{\mathrm{d} m_{\mathrm{v}}}{\mathrm{d} t}+\frac{\mathrm{d} m_{\mathrm{c}}}{\mathrm{d} t}
$$

where $m_{\mathrm{w}}, m_{\mathrm{v}}$ and $m_{\mathrm{c}}$ are the moisture, volatile and char mass in the coal particle ${ }^{1}$.

\subsection{Interphase Exchange Terms}

To facilitate the interphase coupling, a volume must be defined on each discrete segment of the ODT line to convert the extensive particle source terms to intensive terms. The volume is defined in terms of the ODT grid spacing $(\Delta y)$, diameter of the jet $\left(D_{j}\right)$, and coal feed rate, $\dot{m}_{c}$, as $V_{\text {cell }}=$ $\Delta y A_{\text {cell }}=\Delta y D_{j} \dot{m}_{c} / n_{\mathrm{p}}$ with the number of particles in the simulation can be calculated by $n_{p}=\left(\dot{m}_{c} \zeta_{\mathrm{p}}\right)\left(\rho_{\text {coal }} \frac{\pi}{6} d_{\mathrm{p}}^{3}\right)^{-1}$, where $\rho_{\text {coal }}, d_{\mathrm{p}}$ and $u_{\mathrm{p}}$ are initial coal particle density, diameter and velocity, respectively and $\zeta_{\mathrm{p}}=d_{\mathrm{p}} / u_{\mathrm{p}}$. Second-order interpolation between particles and the background mesh is used, consistent with the order of accuracy of the other terms in the numerical scheme.

The momentum exchange terms which appear in the gas and particle momentum balances are

$$
S_{\mathrm{p} \vec{u}}=-\frac{m_{\mathrm{p}} f_{\mathrm{d}}}{\tau_{\mathrm{p}} V_{\text {cell }}}\left(\vec{u}-\vec{u}_{\mathrm{p}}\right)
$$

where $\tau_{\mathrm{p}}=\mathrm{d}_{\mathrm{p}}^{2} / 18 v_{\mathrm{g}}$ is the particle relaxation time [4] and $f_{\mathrm{d}}$ is the drag coefficient.

The species exchange terms in Eq. (5) for single coal particle can be written as:

$$
S_{\mathrm{p} Y_{i}}=\left(\frac{\mathrm{d} m_{i}}{\mathrm{~d} t}\right)^{\text {Evap }}+\left(\frac{\mathrm{d} m_{i}}{\mathrm{~d} t}\right)^{\text {Dev }}+\left(\frac{\mathrm{d} m_{i}}{\mathrm{~d} t}\right)^{\text {Oxid }}+\left(\frac{\mathrm{d} m_{i}}{\mathrm{~d} t}\right)^{\text {Gasif }}
$$

The devolatilization and evaporation models release mass into the gas phase only whereas char oxidation/gasification involve heterogeneous reactions that both consume and produce gas phase species.

\footnotetext{
${ }^{1}$ The mineral (ash) content in the particle is assumed to be constant
} 
The energy exchange terms for the gas Eq. (4) and particle Eq. (9) phases are given as

$$
\begin{aligned}
S_{\mathrm{p} e_{0}} & =\alpha\left(S_{\mathrm{p}, \mathrm{CO}} \Delta H_{\mathrm{CO}}+S_{\mathrm{p}, \mathrm{CO}_{2}} \Delta H_{\mathrm{CO}_{2}}\right)^{\text {Oxid }} \\
& +\alpha\left(\frac{\mathrm{d} m_{\mathrm{c}}}{\mathrm{d} t}\right)_{\mathrm{H}_{2} \mathrm{O}} \Delta H_{\mathrm{H}_{2} \mathrm{O}}^{\mathrm{Gasif}} \\
& +\alpha\left(\frac{\mathrm{d} m}{\mathrm{~d} t}\right)_{\mathrm{CO}_{2}} \Delta H_{\mathrm{CO}_{2}}^{\mathrm{Gasif}} \\
S_{\mathrm{p}, T} & =\frac{1-\alpha}{m_{\mathrm{p}} C_{\mathrm{p}}}\left(S_{\mathrm{p}, \mathrm{CO}} \Delta H_{\mathrm{CO}}+S_{\mathrm{p}, \mathrm{CO}_{2}} \Delta H_{\mathrm{CO}_{2}}\right)^{\text {Oxid }} \\
& +\frac{1-\alpha}{m_{\mathrm{p}} C_{\mathrm{p}}}\left(\frac{\mathrm{d} m_{\mathrm{c}}}{\mathrm{d} t}\right)_{\mathrm{H}_{2} \mathrm{O}}^{\mathrm{Gasif}} \Delta H_{\mathrm{H}_{2} \mathrm{O}}^{\mathrm{Gasif}} \\
& +\frac{1-\alpha}{m_{\mathrm{p}} C_{\mathrm{p}}}\left(\frac{\mathrm{d} m_{\mathrm{c}}}{\mathrm{d} t}\right)_{\mathrm{CO}_{2}}^{\mathrm{Gasif}^{\mathrm{G}}} \Delta H_{\mathrm{CO}_{2}}^{\mathrm{Gasif}} \\
& +\frac{1}{m_{\mathrm{p}} C_{\mathrm{p}}}\left(S_{\mathrm{p}, \mathrm{H}_{2} \mathrm{O}}\right)^{\text {Evap }} \lambda_{\text {Evap }}
\end{aligned}
$$

where $\Delta H$ is the enthalpy of reaction, $\left(S_{\mathrm{p}, \mathrm{H}_{2} \mathrm{O}}\right)^{\text {Evap }}=-\frac{\mathrm{d} m_{\mathrm{w}}}{\mathrm{d} t}$ is the evaporation rate (see Eq. (15)), $\lambda_{\text {Evap }}$ is the latent heat of vaporization for water, $\alpha$ is percentage of energy that released to the gas and $1-\alpha$ is the percentage of energy absorbed by the particle. In the studies explored in this work, the value of $\alpha$ has negligible impact on the predicted flame stand-off since the rate of devolatilization (not char oxidation/gasification) is the dominant factor determining the flame stand-off. In this study, $\alpha=0.3$ is used.

\subsection{Particle Physics Sub-Models}

The models governing coal behavior in the combustion process are discussed in detail in [8] and are briefly summarized here. It was assumed that coal particle is consist of four main constituents: moisture, volatiles, char and ash.

A model based on the partial pressure of water in the gas phase and the particle temperature determines the moisture evolution,

$$
\frac{\mathrm{d} m_{\mathrm{w}}}{\mathrm{d} t}=k_{v}\left(\frac{P_{\mathrm{H}_{2} \mathrm{O}, \mathrm{sat}}}{\mathrm{R} T_{\mathrm{p}}}-\frac{P_{\mathrm{H}_{2} \mathrm{O}}}{\mathrm{R} T_{\mathrm{g}}}\right) A_{\mathrm{p}} M_{w, \mathrm{H}_{2} \mathrm{O}}
$$

where $k_{v}, P_{\mathrm{H}_{2} \mathrm{O} \text {,sat }}, P_{\mathrm{H}_{2} \mathrm{O}}$ and $M_{w, \mathrm{H}_{2} \mathrm{O}}$ are the mass transfer coefficient [23], saturation pressure, partial pressure and molecular weight of water, respectively.

For devolatilization, the CPD model is utilized [14]. The model requires the solution of 18 ODEs on each coal particle to determine the quantities related to devolatilization as well as char production. The volatiles produced by the CPD model include, $\mathrm{CO}_{2}, \mathrm{CO}, \mathrm{CH}_{4}, \mathrm{C}_{2} \mathrm{H}_{2}, \mathrm{HCN}, \mathrm{NH}_{3}, \mathrm{H}$ and $\mathrm{H}_{2} \mathrm{O}$, and the relative production rates of these species change through the simulation [14]. These production rates are coupled to the gas-phase chemistry via Eq. (13). The required model parameters for Illinois \#6 coal type used in this work, are extracted form [6, 31].

The heterogenous reactions of char account for oxidation and gasification. For oxidation process, a $n^{\text {th }}$-order Langmuir-Hinshelwood model[22] implemented where the rate of char oxidation is a function of oxygen partial pressure at particle surface and particle temperature. The char oxidation process releases $\mathrm{CO}$ and $\mathrm{CO}_{2}$ in a ratio proposed by Tognotti et al. [36]. A set of $n^{\text {th }}$-order Arrhenius equations determines the gasification reactions rate $[15,38]$. These models consume $\mathrm{O}_{2}, \mathrm{H}_{2} \mathrm{O}$ and $\mathrm{CO}_{2}$ from the gas and release $\mathrm{CO}, \mathrm{CO}_{2}$ and $\mathrm{H}_{2}$.

The mass of ash is assumed constant in lifetime of particle and the evolution of particle surface area is accounted using a modified random pore model $[19,21]$.

\subsection{Turbulence Model}

In ODT, turbulent mixing is modeled through a series of stochastic "eddy events" or simply "eddies" [16, 35]. By construction, eddies conserve momentum, energy and mass over the interval on which they act. Their $\operatorname{size}\left(\ell_{e}\right)$, lifetime $\left(\tau_{e}\right)$ and location are influenced by the local energetics of the flow field $[16,35]$. This allows the ODT model to naturally capture key turbulence properties such as the $-5 / 3$ energy cascade in isotropic turbulence [16]. The frequency at which eddies occur is dictated by eddy rate distribution, $\lambda=C / \ell_{e}^{2} \tau_{e}$, which is directly influenced by the "eddy rate constant" $(C)$. The impact of the value chosen for $C$ on the model's ability to capture statistics in turbulent jets was studied by [25].

The particle-eddy interaction is considered in this work using a continuos formulation of Type-C interaction proposed by Schmidt [29]. Further details of the model are described by [25].

\section{Computational Configuration}

Details of the furnace and burner considered here are reported in [28]. The downward-fired burner consists of a primary stream with $15.8 \mathrm{~mm}$ ID and $21.3 \mathrm{~mm}$ OD and a secondary stream with $35.05 \mathrm{~mm}$ ID. The velocities of the primary and secondary streams are 6.3 and $14.9 \mathrm{~m} / \mathrm{s}$, respectively (Fig. 3 illustrates the initial velocity profiles). The composition and temperature of the inlet streams and co-flow are reported in Table 1. In this work, the composition of effluent gas is applied for co-flow ${ }^{2}$. Illinois \#6 coal particles of size $68.5 \mu \mathrm{m}$ and density $1450 \mathrm{~kg} / \mathrm{m}^{3}$ are fed at a rate of $5.26 \mathrm{~kg} / \mathrm{hr}$. The coal particles are assumed to have same temperature and velocity of carrier gas (primary stream). The ultimate and proximate analysis of Illinois \#6 coal are reported in [27].

Table 1: Composition and temperature of burner streams and co-flow gas.

\begin{tabular}{ccccc}
\hline & $\mathrm{T}$ & $\mathrm{O}_{2}$ & $\mathrm{CO}_{2}$ & $\mathrm{H}_{2} \mathrm{O}$ \\
\cline { 3 - 5 } & $(\mathrm{K})$ & \multicolumn{3}{c}{ volume fraction } \\
\hline Primary & 305 & $0.0-0.101$ & $1.0-0.899$ & 0.0 \\
Secondary & 489 & $0.488-0.467$ & $0.512-0.533$ & 0.0 \\
Co-flow & 1283 & 0.048 & 0.815 & 0.137 \\
\hline
\end{tabular}

\footnotetext{
${ }^{2}$ This assumption is motivated by the recirculation of products upstream to the inlet. Although not ideal, in the absence of experimental measurement of the near-burner entrained gases this was reasonable.
} 
To study the effect of the radiative temperature and mixing rate on the flame stand-off distance, a parametric study was undertaken, as summarized in Table 2. For each configuration, approximately 300 realizations are performed to obtain reasonable statistics. Temporal and spatial resolutions are $200 \mathrm{~ns}$ and $200 \mu \mathrm{m}$, respectively, which yield grid-converged statistics for the flame stand-off distance.

\begin{tabular}{ccccc}
\multicolumn{5}{c}{ Table 2: Parameters for simulations considered herein. } \\
\hline Case & $x_{\mathrm{O}_{2}}^{\mathrm{P}}$ & $x_{\mathrm{O}_{2}}^{\mathrm{S}}$ & $C$ & $T_{\text {rad }}(\mathrm{K})$ \\
\hline $\mathrm{A} .1$ & 0.0 & 0.488 & 10 & 1280 \\
$\mathrm{~A} .2$ & 0.0 & 0.488 & 10 & 1450 \\
$\mathrm{~A} .3$ & 0.0 & 0.488 & 10 & 1600 \\
$\mathrm{~A} .4$ & 0.0 & 0.488 & 10 & 1800 \\
$\mathrm{~B} .1$ & 0.0 & 0.488 & 2 & 1600 \\
$\mathrm{~B} .2$ & 0.0 & 0.488 & 20 & 1600 \\
C.1 & 0.101 & 0.467 & 10 & 1600 \\
\hline
\end{tabular}

The governing equations and models outlined previously are solved using a fully coupled, compressible algorithm with an explicit time integration scheme and a secondorder finite volume spatial discretization. Characteristic boundary conditions [34] are applied on the domain boundaries.

\section{Results}

The simulation predictions are compared to experimental data where flame stand-off distance is used as a metric. Characterizing the ignition point and flame stand-off is a challenge in both experiment and simulation. The experimental methodology to identify the flame stand-off distance (discussed in [39]) can be summarized as:

- A sequence of images taken by a CMOS camera were collected and converted to gray scale.

- Flame edges were defined to be where the intensity gradient is at the maximum.

- The average intensity value at the detected edges was used to define a threshold value.

- The calculated threshold value was applied to the gray scale image to obtain the flame stand-off distance.

These steps were applied to the sequence of approximately 6000 images to obtain a probability density function (PDF) for the flame stand-off distance [28].

The simulations do not allow for a direct comparison with experimental data since a reliable model for light emission in the spectra captured by the CMOS camera would be a significant undertaking. In this work, a simple model based on the local mole fraction of acetylene $\left(\mathrm{C}_{2} \mathrm{H}_{2}\right)$ and the gas temperature is used:

$$
I_{\mathrm{C}_{2} \mathrm{H}_{2}}=x_{\mathrm{C}_{2} \mathrm{H}_{2}} \times T_{\mathrm{g}}^{4}
$$

Acetylene was chosen out of convenience since it was available in the chemical mechanism, despite the fact that soot from coal does not come from acetylene in general [7]. While the definition of intensity in (16) may influence the quantitative location of the characterized flame standoff distance, it has minimal effect on the trends and conclusions presented herein. Given that the purpose of this work is to explore the impact of models as well as system parameters on the simulation prediction and evaluate the ability of the ODT model to capture the salient feature of ignition in turbulent coal combustion, this limitation was deemed acceptable. With Eq. (16) as an approximation for the light emission intensity, a procedure analogous to the experimental one outlined above is used to define the flame stand-off:

- $I_{\mathrm{C}_{2} \mathrm{H}_{2}}$ is determined via Eq. (16), and the flame edges are defined where the gradient is at the maximum.

- The average $I_{\mathrm{C}_{2} \mathrm{H}_{2}}$ is used to define a threshold value.

- The flame stand-off distance is identified where $I_{\mathrm{C}_{2} \mathrm{H}_{2}}$ first crosses the threshold.

For each simulation listed in Table 2, the above procedure is applied to obtain a PDF of the flame stand-off distance for comparison with the experimental data.

Figure 1 shows the average of normalized volatile $\left(\left\langle m_{v}\right\rangle\right)$ and char mass $\left(\left\langle m_{c}\right\rangle\right)$ of coal particles for case A.3, as well as the relative contribution of char oxidation to the overall char consumption rate (the balance being char gasification $)^{3}$. Figure 1 indicates that the onset of devolatilization occurs around $\ell \approx 0.2 \mathrm{~m}$ and that char consumption, dominated by gasification reactions, is active beginning at $\ell \approx 0.3 \mathrm{~m}$. The vertical bars indicate the maximum and minimum values observed among the coal particles at a given location (across all ODT realizations), and are due to particle dispersion, which subjects the particles to different gas environments.

The ensemble-averaged spatial profiles for a few gas-phase properties for case A.3 are shown in Fig. 2. The gas phase temperature (Fig. 2a) at the centerline resists heating due to the thermal inertia of the coal particles. A volatile cloud ${ }^{4}$ starts to form at the centerline at $\ell \approx 0.25 \mathrm{~m}$, displacing and consuming $\mathrm{O}_{2}$ as the coal temperature increases and devolatilization nears completion around $\ell \approx 0.45 \mathrm{~m}$. The homogenous oxidation of the volatiles at $\ell \approx 0.25-0.35$ $\mathrm{m}$ produces $\mathrm{OH}$ as an intermediate species as shown in Fig. 2d. The notable production of $\mathrm{OH}$ after $\ell \approx 0.5 \mathrm{~m}$ indicates the homogenous reaction (oxidation) of the accumulated fuel at the center of the furnace.

By $\ell \approx 0.4 \mathrm{~m}$, homogenous reactions have consumed most of the oxygen in the devolatilization region (as evidenced by Fig. 2b) and the temperatures of the gas and particles are high enough that the char reactions become important. Fig. 1 shows the fraction of the char consumption that is

\footnotetext{
${ }^{3}$ Space-time mapping was applied using the mean axial velocity (which evolves in time) to determine an approximate downstream distance for the ODT line. See [35] for details.

${ }^{4}$ The volatile cloud includes contributions from neighboring particles. A study of ignition delay for single coal particles has already been considered in [8].
} 
due to char oxidation (with the balance due to gasification), and indicates that gasification reactions (reaction of char with $\mathrm{H}_{2} \mathrm{O}$ and $\mathrm{CO}$ ) play a very substantial role in the char consumption. Indeed, Figs. $2 \mathrm{c}$ and $2 \mathrm{e}$ indicate that the $\mathrm{CO}_{2}$ is largely consumed by char oxidation, being replaced with a substantial amount of CO. At $\ell \approx 0.45-0.6$ $\mathrm{m}$ the gasification reactions are accountable for $60-80 \%$ of char consumption. In addition, due to the lack of oxygen around the coal particles after $\ell \approx 0.45$ the the char oxidation reaction favors $\mathrm{CO}$ (rather than $\mathrm{CO}_{2}$ ) production.

A final observation on Fig. 1 is that the overlap of char oxidation/gasification with devolatilization suggests that these processes should be allowed to occur concurrently rather than assumed to occur sequentially, as has been assumed in some proposed modeling approaches $[12,13,37]$.

Since this work is focussed on characterizing flame standoff distance, the simulation predictions at the longer distances, where subsequent mix-out of the rich zone and burnout occur, are not discussed in here.

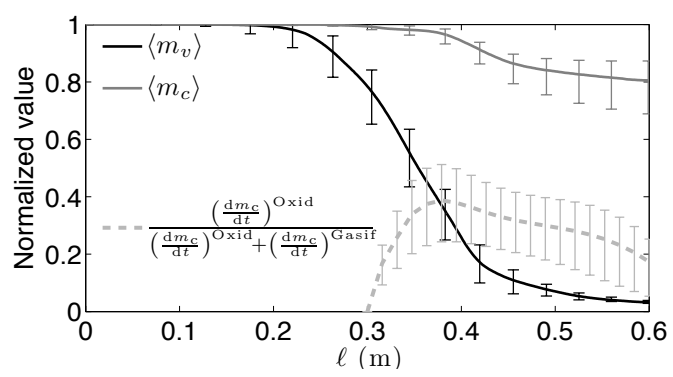

Figure 1: Average of normalized volatile and char mass for case A.3. The relateive char oxidation contribution in char consumption is represented by $\left(\frac{\mathrm{d} m_{\mathrm{c}}}{\mathrm{d} t}\right)^{\text {Oxid }}\left[\left(\frac{\mathrm{d} m_{\mathrm{c}}}{\mathrm{d} t}\right)^{\text {Oxid }}+\left(\frac{\mathrm{d} m_{\mathrm{c}}}{\mathrm{d} t}\right)^{\text {Gasif }}\right]^{-1}$

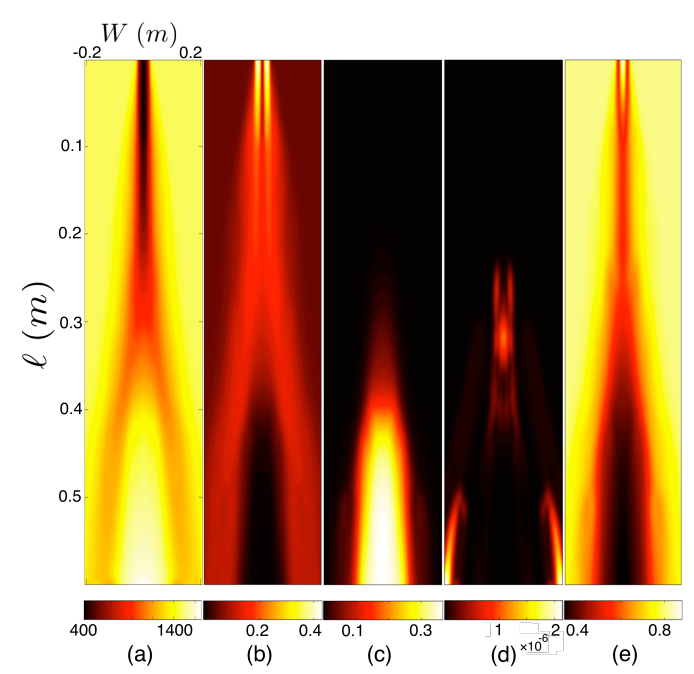

Figure 2: Species mole fraction and gas temperature contours for case A.3. a) gas temperature (K). b) $\mathrm{O}_{2}$, c) $\mathrm{CO}$, d) $\mathrm{OH}$, e) $\mathrm{CO}_{2}$ mole fraction

\subsection{Impact of Mixing}

As discussed in $\$ 2.5$, the impact of $C$ as an ODT model parameter is to directly influence the eddy frequency (turbulence intensity). This section explores the effect of this pa- rameter on the predicted flame stand-off ${ }^{5}$. Figure 3 shows the ensemble averaged streamwise (axial) velocity profiles, $\langle u\rangle$, for different $C$ values at two downstream locations, and provides an indication of the effect of $C$ on entrainment. As evidenced by the velocity profiles in Figure 3, increasing $C$ has a direct influence on the frequency of eddies and thus raises the mixing rate. This figure is provided to give a sense of the range of mixing intensities obtained by changes in $C$.

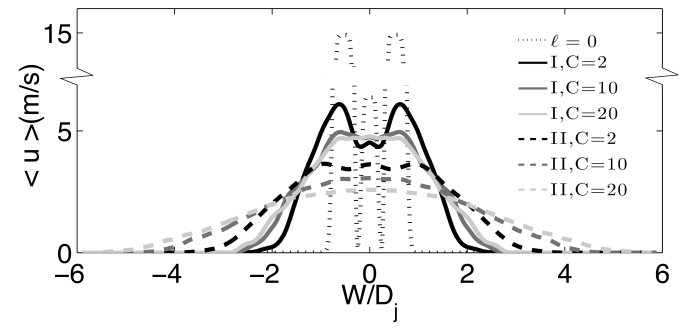

Figure 3: Velocity profiles for case B.1 $(C=2)$, A.3 $(C=10)$ and B.2 $(C=20)$ (see Table 2). I and II represent $\ell / D_{\mathrm{j}}=2.5$ and $\ell / \mathrm{D}_{\mathrm{j}}=8.5$, respectively, where $D_{j}$ is the primary jet inner-diameter. The initial velocity profile is also shown for reference.

The coal particle temperature, averaged across all particles and all ODT realization at a given downstream length, is illustrated in Fig. 4 for three values of $C$. The vertical bars indicate the minimum and maximum observed particle temperatures for all ODT realizations. An increase in $C$ leads to greater particle dispersion which, for $\ell<0.35$, tends to move some particles into hotter regions (see Fig. 2). This, in turn, leads to earlier ignition and shorter flame standoff distance, as can also be inferred from Fig. 4.

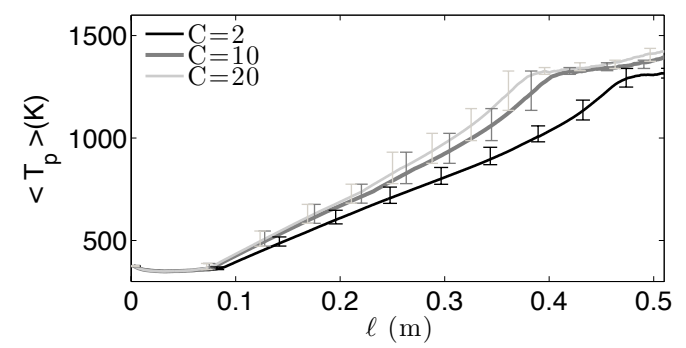

Figure 4: Averaged particles temperature for cases B.1 $(C=2)$, A.3 $(C=10)$ and B.2 $(C=20)$ (see Table 2$)$.

Figure 5 shows the the experimentally observed flame stand-off as well as the results for different eddy rate constants $(C)$. The minimum characterized flame stand-off distance (i.e., the position of the left-most tail of the PDF) is relatively insensitive to the mixing rate, suggesting that the lower-limit for the flame standoff is kinetically controlled. The width of PDFs in Fig. 5 shrinks as $C$ value increases, consistent with the suggestion of a kineticallylimited lower limit for flame standoff around $\ell=0.22$. Physically, larger mixing rates result in higher particle dispersion as well as introduction of hot product gases into

\footnotetext{
${ }^{5}$ The effect of this parameter on turbulent reacting jets was studied by [25], where $C=10$ was suggested as a reasonable value.
} 
the devolatilization region. As discussed previously (see Fig. 4), this increases the mean particle temperature resulting in higher devolatilization rates and resulting in a narrowing of the flame stand-off PDF.

To further establish the relative importance of mixing versus reaction on the flame stand-off prediction, the oxygen mole fraction of the jet primary stream was increased from 0 (case A.3) to 0.101 (case C.1) while the overall oxygen flow in the jet (primary and secondary streams) is kept constant. Other properties such as streams velocity and temperature are preserved (see Table 1 for details). Figure 6 illustrates the effect of the primary stream composition on flame stand-off, where the experiment data (dashed line) is for $x_{\mathrm{O}_{2}}^{p}=0$. The minimum distance of flame stand-off PDF that represents the kinetic limited ignition is not affected by a change in oxygen concentration change in the primary stream, further suggesting that the minimum flame stand-off is kinetically limited. There is a slight effect of partial premixing $\left(x_{\mathrm{O}_{2}}^{p}=0.101\right)$ on the larger flame stand-off distance, indicating that the effects of mixing (for $x_{\mathrm{O}_{2}}^{p}=0$ ) become more important in determining flame standoff.

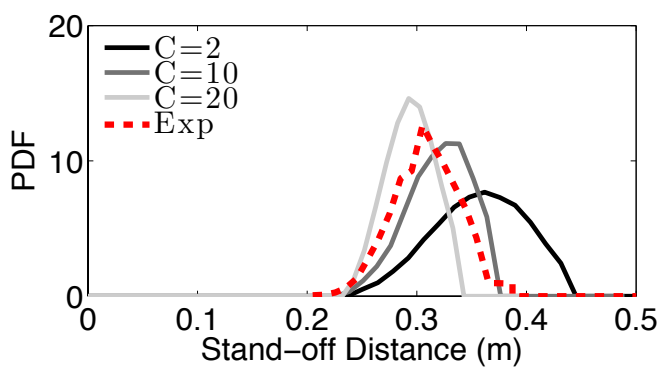

Figure 5: Mixing effect on flame stand-off (cases B.1, A.3, and B.2)

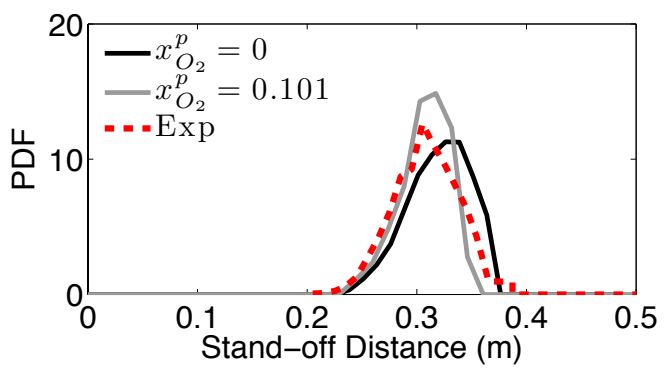

Figure 6: Effect of primary oxygen concentration on flame stand-off distance (cases A.3 and C.1)

\subsection{Influence of Radiative Temperature}

In the particle energy equation, Eq. (9), an effective radiative temperature is considered as the radiation source. To characterize the impact of this effective radiativetemperature on flame stand-off distance, a range of effective radiative temperatures from $1280 \mathrm{~K}$ to $1800 \mathrm{~K}$ was considered. The experimentally reported "nominal wall temperature" is $1280 \mathrm{~K}$, but this is likely an underestimate of the effective radiative temperature since there are high temperature flame zones nearby. Figure 7 shows the influence of radiative-temperature on flame stand-off distance. As expected, higher effective radiative-temperatures result in a smaller stand-off distance. The significant influence of radiative temperature on flame stand-off distance was also reported by [24], in which LES of the oxy-coal combustor was performed.

As discussed in 4.1, kinetically-limited regimes are characteristic of the shorter distances. In Fig 7, the shortest distances of PDFs are moving notably with changes in radiative temperature that emphasize the dominancy of kinetic limited regimes in these distances. However, as discussed before the minimum flame stand-off is almost insensitive to the mixing rate (see Fig. 5). Additionally, the PDF width decreases with increasing in radiative temperature; this can be explained by the rate of volatile release.

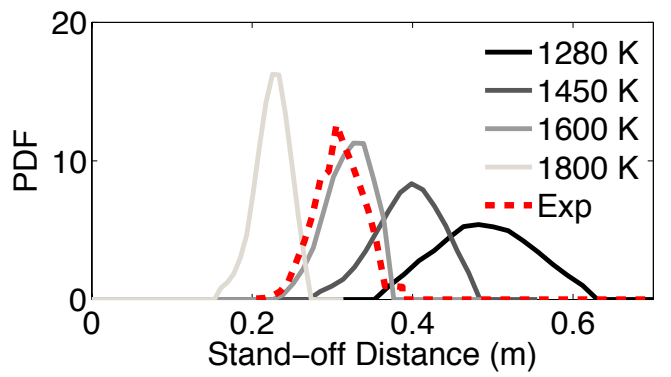

Figure 7: Effect of radiative temperature on flame stand-off (cases A.2, A.2, A.3 and A.4).

Figure 8 illustrates the averages of normalized volatile mass in the coal particles at the downstream distance where ignition occurs $\left(\left\langle m_{v}\right|\right.$ Flame $\left.\rangle\right)$. The vertical bars indicate the range of normalized volatile mass observed at the corresponding flame stand-off distance. Of particular significance, Fig. 8 suggests that there is a minimum devolatilization required to achieve ignition and that this amount is nearly constant over a range of radiative temperatures, despite the large difference in devolatilization rates at the various radiative temperatures. The larger devolatilization rates at higher radiative temperatures simply narrow the flame stand-off PDF, providing a more uniform ignition.

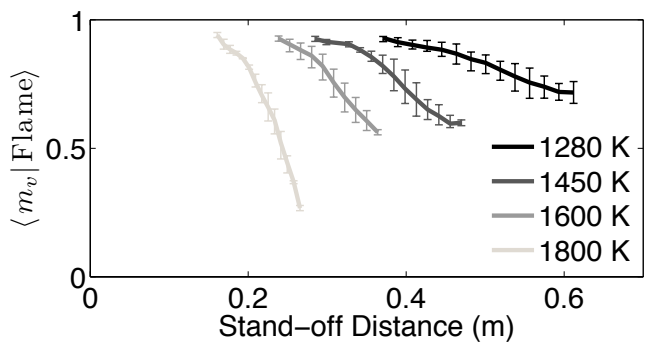

Figure 8: Residual volatile fractions in coal particles at the identified flame stand-off distance

\section{Conclusions}

Simulations of oxy-coal flames have been performed using the ODT model. Because the ODT model must only resolve the physics in one spatial dimension, it allows incorporation of detailed thermochemistry models that would be unaffordable in DNS. The fully coupled governing equations in the particle and gas phases including mass, mo- 
mentum and energy are solved with detailed gas-phase kinetics and a high-fidelity devolatilization model (CPD). Comparison to experimental data indicate that the model captures the flame standoff distance, a key marker of ignition, quite well. Results indicate that char gasification plays an important role during the later phases of the devolatilization process after homogeneous ignition occurs.

The impact of mixing rate on the flame stand-off prediction and physics of system was also considered. An increase in mixing rate decreases the likelihood of ignition at longer distances, however, it does not affect the short distance, suggesting a kinetically limited lower bound to flame standoff. A study on impact of radiative temperature on simulation prediction is performed. Results show that, radiative temperature significantly influences on flame stand-off distance, modifying both mean and PDF of flame stand-off shape. Finally, the simulations performed here consider a uniform particle size, and these conclusions must be considered bearing that in mind.

\section{Acknowledgements}

The authors express their special thanks to Dadmehr Rezaei for his help and for providing the experimental data. This material is based upon work supported by the Department of Energy under Award Number DENT0005015 as well as NSF PetaApps award 0904631. The views and opinions of authors expressed herein do not necessarily state or reflect those of the United States government or any agency thereof.

[1] D. B. Anthony and J. B. Howard, Coal devolatilization and hydrogastification, AICHE J., 22 (1976), pp. 625-656.

[2] S. Badzioch and P. G. W. Hawksley, Kinetics of thermal decomposition of pulverized coal particles, Ind. Eng. Chem. Process Design and Development, 9 (1970), pp. 521-530.

[3] B. S. Brewster, L. L. Baxter, and L. D. Smoot, Teatment of coal devolatilization in comprehensive combustion modeling, Energy \& Fuels, 2 (1988), pp. 362-370.

[4] C. T. Crowe, J. D. Schwarzkodf, M. Sommerfeld, and Y. Tsuji, Multiphase Flows with Droplets and Particles, CRC Press, second ed., 2012.

[5] R. C. da Silva, T. Kangwanpongpan, and H. J. Krautz, Flame pattern, temperatures and stability limits of pulverized oxy-coal, Fuel, 115 (2014), pp. 507-520.

[6] T. H. Fletcher, A. R. Kerstein, R. J. Pugmire, M. S. Solum, and D. M. Grant, Chemical percolation model for devolatilization. 3. direct use of 13C NMR data to predict effects of coal type, Energy \& Fuels, 6 (1992), pp. 414-431.

[7] T. H. Fletcher, J. Ma, J. R. Rigby, A. L. Brown, and B. W. WebB, Soot in coal combustion systems, Prog. Energy Combust. Sci., 23 (1997), pp. 283-301.

[8] B. GoshaYeshi and J. C. Sutherland, A comparison of various models in predicting ignition delay in single-particle coal combustion, Combust. Flame, (2014).

[9] D. M. Grant, R. J. Pugmire, T. H. Fletcher, and A. R. Kerstein, Chemical model of coal devolatilization using percolation lattice statistics, Energy \& Fuels, 3 (1989), pp. 175-186.

[10] E. S. Hecht, C. R. Shaddix, A. Molina, and B. S. Haynes, Effect of $\mathrm{CO} 2$ gasification reaction on oxy-combustion of pulverized coal char, Proc. Combust. Inst, 33 (2011), pp. 1699-1706.

[11] F. P. Incropera and D. P. DeWitt, Introduction to Heat Transfer, John Wiley \& Sons, fourth ed., 2002.

[12] R. Jovanovic, A. Milewska, B. Swiatkowski, A. Goanta, and H. SpLIETHоF, Numerical investigation of influence of homogeneous/heterogeneous ignition/combustion mechanisms on ignition point position during pulverized coal combustion in oxygen enriched and recycled flue gases atmosphere, Int. J. Heat and Mass Trans., 54 (2011), pp. 921-931.
[13] R. Jovanovic, B. Rašuo, P. Stefanovic, D. Cvetinovic, and B. Swiatкоwsкi, Numerical investigation of pulverized coal jet flame characteristics under different oxy-fuel conditions, Int. J. Heat and Mass Trans., 58 (2013).

[14] R. S. Jupudi, V. Zamansky, and T. H. Fletcher, Prediction of light gas composition in coal devolatilization, Energy \& Fuels, 23 (2009), pp. 3063-3067.

[15] S. KaJtTANI, S. HaRA, AND H. Matsuda, Gasification rate analysis of coal char with a pressurized drop tube furnace, Fuel, 81 (2002), pp. 539-546.

[16] A. R. KersteIn, One-dimensional turbulence: model formulation and application to homogeneous turbulence, shear flows, and buoyant stratified flows, J. Fluid Mech., 392 (1999), pp. 277-334.

[17] H. Kobayashi, J. B. Howard, and A. F. Sarofim, Coal devolatilization at high temperatures, Proc. Combust. Inst., 16 (1977), pp. $411-$ 425.

[18] D. O. Lignell and D. S. Rappleye, One-dimensional-turbulence simulation of flame extinction and reignition in planar ethylene jet flames, Combust. Flame, 159 (2012), pp. 2930-2943.

[19] H. Liu, C. Luo, M. KaneKo, S. Kato, and T. Koлma, Unification of gasification kinetics of char in $\mathrm{CO} 2$ at elevated temperatures with a modified random pore model, Energy \& Fuels, 17 (2003), pp. 961970.

[20] Y. Liu, M. Geier, A. Molina, and C. R. Shaddix, Pulverized coal stream ignition delay under conventional and oxy-fuel combustion conditions, Int. J. of Greenhouse Gas Control, 5 (2011), pp. S36S46.

[21] T. Morimoto, T. OchiaI, S. Wasaka, and H. Oda, Modeling on pore variation of coal chars during CO2 gasification associated with their submicropores and closed pores, Energy \& Fuels, 20 (2006).

[22] J. J. Murphy and C. R. Shaddix, Combustion kinetics of coal chars in oxygen-enriched environments, Combust. Flame, 144 (2006), pp. $710-729$.

[23] G. Neluis and S. Klein, Heat Transfer, Cambridge, 2008.

[24] J. Pedel, J. N. Thornock, ANd P. J. Smith, Ignition of co-axial turbulent diffusion oxy-coal jet flames: Experiments and simulations collaboration, Combust. Flame, 160 (2013), pp. 1112-1128.

[25] N. Punati, An Eulerian One-Dimensional Turbulence Model: Application to Turbulent and Multiphase Reacting Flows, $\mathrm{PhD}$ thesis, Department of Chemical Engineering, The University of Utah, January 2012.

[26] N. Punati, J. C. Sutherland, A. R. Kerstein, E. R. Hawkes, AND J. H. Chen, An Evaluation of the One-Dimensional Turbulence Model: Comparison with Direct Numerical Simulations of $\mathrm{CO} / \mathrm{H} 2$ Jets with Extinction and Reignition, Proc. Combust. Inst., 33 (2011), pp. 1515-1522.

[27] D. ReZaeI, Co-Axial Turblent Diffusion Flames with Directed Oxygen Injection, $\mathrm{PhD}$ thesis, The University of Utah, May 2013.

[28] D. Rezaei, Y. Zhou, J. Zhang, K. E. Kelly, E. G. Eddings, R. J. PugMIRE, M. S. Solum, , AND J. O. L. WendT, The effect of coal composition on ignition and flame stability in coaxial oxy-fuel turbulent diffusion flames, Energy \& Fuels, 27 (2013), pp. 4935-4945.

[29] J. R. ScнмiDT, Stochastic models for the prediction of individual particle trajectories in One Dimensional Turbulence flows, $\mathrm{PhD}$ thesis, University of Arizona, 2004.

[30] J. R. Schmidt, J. O. L. Wendt, and A. R. Kerstein, Non-equilibrium Wall Deposition of Inertial Particles in Turbulent Flow, J. Stat. Phys, 137 (2009), pp. 233-257.

[31] M. A. Serio, D. G. Hamblen, J. R. Markham, and P. R. Solomon, Kinetics of volatile product evolution in coal pyrolysis: Experiment and theory, Energy \& Fuels, 1 (1987), pp. 138-152.

[32] N. Slavinskaya, M. Braun-Unkhoff, and P. Frank, Reduced reaction mechanisms for methane and syngas combustion in gas turbines, Inst. Combust. Tech., 130 (2008), pp. 38-40.

[33] K. L. Smith, L. D. Smoot, T. H. Fletcher, and R. J. Pugmire, The Structure and Reaction process of coal, Plenum Press, New York, 1994.

[34] J. C. Sutherland and C. A. Kennedy, Improved Boundary Conditions for Viscous, Reacting, Compressible Flows, J. Comp. Phys., 191 (2003), pp. 502-524.

[35] J. C. Sutherland, N. Punati, and A. R. Kerstein, A Unified Approach to the Various Formulations of the One-DimensionalTurbulence Model, Institute for Clean and Secure Energy, 2010.

[36] L. Tognotti, J. P. Longwell, ANd A. F. SARofim, The products of the high temperature oxidation of a single char particle in an electrodynamic balance, Proc. Combust. Inst, 23 (1991), pp. 1207-1213. 
[37] M. Vascellari, R. Arora, M. Pollack, and C. Hasse, Simulation of entrained flow gasification with advanced coal conversion submodels. part 1: Pyrolysis, Fuel, 113 (2013), pp. 654-669.

[38] H. Watanabe and M. Otaka, Numerical simulation of coal gasification in entrained flow coal gasifier, Fuel, 85 (2006), pp. 1935-1943.

[39] J. Zhang, K. E. Kelly, E. G. Eddings, and J. O. Wendt, CO2 effects on near field aerodynamic phenomena in $40 \mathrm{kw}$, co-axial, oxy-coal, turbulent diffusion flames, Int. J. of Greenhouse Gas Control, 55 (2011), pp. 547-557. 